\title{
AUTOMATION AND ROBOTICS IN POST DISASTER WASTE MANAGEMENT: POST TSUNAMI SRI LANKA
}

\author{
Gayani Karunasena \\ Lecturer \\ Department of Building Economics, \\ University of Moratuwa, Moratuwa \\ gayani@becon.mrt.ac.lk
}

\author{
Dilanthi Amaratunga \\ Prof., Senior Lecturer \\ School of Built and Human Environment, \\ University of Salford, UK \\ r.d.g.amaratunga@salford.ac.uk
}

\author{
Richard Haigh \\ Dr., Lecturer \\ School of Built and Human Environment, \\ University of Salford, UK \\ r.p.haigh@salford.ac.uk
}

\begin{abstract}
In recent years, automation and robots have been applied at different domains to coordinate collaborative behavior in distributed systems and providing a powerful basis for proactive applications of complex nature, specially in large scale disasters requiring complex tasks to be performed by groups under extreme time and resource constraints. Sri Lanka is still suffering from effects of December 2004 Tsunami disaster. Waste and debris becomes a key issue. Therefore, it is important to explore avenues to optimize post disaster waste management through automation and robotics. Thus, this paper aims to provide a critical review on automation and robotics applications at a post disaster scenario. Comprehensive literature review, documentary survey and field survey are adopted as methods of data collection. Survey revealed capacity constraints of expertise, funds and cultural issues as main challenges. Finally, the paper provides new avenues for effective utilization of automation and robotics through mapping of best practices.
\end{abstract}

\section{KEYWORDS}

Automation and Robotics, Post disaster, Waste Management, Tsunami

\section{INTRODUCTION}

Natural disasters and conflicts continue to devastate communities around the world. It is important to prepare measures for both pre and post disasters to ensure safety and peace of mind to public as well as the environment.

In recent years, automation and robots have been applied at different domains to coordinate collaborative behavior in distributed systems and providing 
a powerful basis for proactive applications of complex nature, especially in large scale disasters requiring complex tasks to be performed by groups under extreme time and resource constraints.

This is not an exception to a developing country like Sri Lanka which was heavily affected by the Asian Tsunami in 2004, especially with emphasis on inadequate knowledge on technology and scarce resources. UNEP report (2005) [1] highlights poor performance of post -Tsunami rehabilitation operations affected by lack of responsive capacities of local government institutions to address needs of an event of such magnitude. Further, inefficient management of resources due to poor coordination and lack of communication among participants in disaster management operations were noted by many other international institutions ((Asian Development Bank (ADB); World Bank (WB); United Nations Development Program (UNDP); European Commission (EC)). Therefore, it is vital for a proper approach which caters to resource matching and effectively coordinate for efficient management at an event of disaster. According to Scalem [2] this can be achieved through efficient utilization of information and communication technologies. They support more timely and enhanced data acquisition, information production, decision making and action coordination.

Purpose of this paper is to present a critical review on automation and robotic applications in post disaster waste management including curial issues of awareness. The feedback will immensely enhance capacities of relevant institutions in Sri Lanka that need to be improved to launch successful post disaster waste management programs and effectively face future challenges similar to the Tsunami.

\section{RESEARCH METHODOLOGY}

Different methodologies are adopted for different parts of this study. Applications of automation and robotics were analyzed based on existing papers and documents, aided by interviews with selective practitioners and experts of the field.

Scope of this study is restricted to a single case study, the Asian Tsunami of 2004 and further, geographically to the Galle Municipal Council area, which is a highly affected city in Sri Lanka. Further, area of concern is restricted to post disaster waste management.

Interviews were conducted during the field survey for data collection. Finally, critical issues towards automation and a set of avenues are identified for effective utilization of information and communication strategies.

\section{OVERVIEW ON POST TSUNAMI WASTE}

Asian Tsunami that hit the coasts of Sri Lanka on 26th December 2004 was an unique experience where nearly one million people (234,000 families) were affected and destroyed US \$900 millions worth of assets and infrastructure in Sri Lanka [3]. This is considered as the highest ever recorded value of disaster/ destruction damage caused by a single event in Sri Lanka.

In a disaster, generation of waste is unavoidable. This causes serious environmental and economical burdens on normal living conditions, reconstruction phases as well as on general municipal waste collection processes. Therefore, waste management and disposal has emerged as a critical issue in responding to a disaster. Further, disasters are so closely intertwined with environment and proper environmental management and governance is essential for long term peace, stability and security in disaster prone countries, particularly, in developing countries where affected communities rely heavily on natural resources for survival.

A specific proportional breakdown of Tsunamigenerated waste is not available. A rapid inspection of waste at damaged areas, unauthorized dumps and unplanned landfills indicate that, by volume, a large part of waste consists of spoiled soil, damaged building material and vegetative matter and smaller proportions of plastic, metal and items of undetermined origin. No significant presence of hazardous chemicals or technological items was noted. Similarly, sampling results of City of Galle's waste stream revealed that over $77 \%$ of waste was of biodegradable organic waste and another $5.5 \%$ was of paper products and few traditionally recyclable materials [4]. 
Next session of the paper provides a critical review on applications of automation and robotics in waste management at post Tsunami Sri Lanka including critical issues and available avenues mapped from best global practices.

\section{POST TSUNAMI APLLICATIONS OF AUTOMATION AND ROBOTICS}

Information management gains the highest priority and significance. As indicated in the previous session there is no specific breakdown of waste generated during the Tsunami in 13 districts. This explains absence of accurate information gathering (MIS - Management Information System) which identifies as the key requirement of emergency response scenarios. According to Scalem [2], this disables end-users in interacting and sharing information on real time platforms leading to ineffective management of waste. Further, this disables development of sophisticated systems such as agent based systems, networks, Electronically Enabled Disaster Management (EEDM) etc.

National Environmental Authority, Predeshiya Sabhas and Urban and Municipal Councils are key players in management of waste. Although such responsible organizations have taken steps to address issues of waste management, due to lack of necessary networks and linkages enabling widespread changes has lead to unsuccessful programs. This is due to poor coordination and lack of communication among participants in disaster waste management operations. With introduction of distributed and decentralized information networks above issues can be addressed. However, according to Scalem et al. [5] existence of wireless communication infrastructure alone does not ensure efficient and effective disaster management. The existing disaster management approaches are quite unstructured and usually centralized in nature with instructions flowing in a fixed hierarchy. This results in poor resource management causing inefficiency. Hence there is a need for demand-driven, user centric, decentralized, hierarchy independent information-exchange approaches wherein even the end user is empowered accordingly for quick and effective decision-making promoting efficient resource sharing. Implementations of these concepts are difficult in Sri Lanka due to cultural impacts. As a way forward, community-based activities need to be encouraged since it is deeply rooted in the society and culture of an area, enabling people to express their real needs and priorities, allowing problems to be defined correctly and responsive measures to be properly designed and implemented.

Proper waste management practices include separation, removal, recycling and safe storage of waste. In a disaster situation, it may not be practical to employ a system of waste separation due to amount of debris created and time and labor constraints. According to Selvendran [6], waste separation system became impractical at a post disaster situation as cleanup and recovery became the first priority. Author's opinion is use of robots for separation for waste can be considered as a new avenue for research when compared with high labor intensive nature of such work and psychological conditions of victims in an immediate aftermath. However, there are already increasing reports of robots rescuing victims of disaster in the world [7].

There was considerable recycling of building debris by individual homeowners who attempted to re-use material in reconstruction of houses and recycling through "cash for work" programs organized by NGOs which were environmentally beneficial while helping livelihood restoration. However, there were hardly any massive recycling programs due to poor local expertise and capacities in recycling, composting and environmental management. Further, it is indicated that waste removal programs conducted with collaboration of NGOs do not consistently meet current best practices due to a lack of readily available guidance, practical procedures and resources. This indicates the importance of enhancing capacities of disaster management authorities or providing mechanisms for assistance in decision making. According to Fiedrich and Burghardt [8] introduction of agent based systems for disaster management can overcome many barriers identified above. Agent based simulation systems allow creation of realistic post disaster environments and agent based decision support systems support disaster managers at different levels. Further, these can be used as computer training programs to improve awareness of the 
public as well as intuitions. Critical challenge on this aspect is that most victims of Tsunami are lowincome less educated people living along coastal lines of Sri Lanka. Therefore, any significant social change needs to occur within context of individual attitudes and behaviors. Thus this is becoming a critical issue impacting on success. As a way forward, innovative movements need to be arranged to create individual awareness and build cohesive communities among the community groups which will lead for success. Further, practical efforts such as Galle district waste management project (COWAM: Construction Waste Management) should be scaled-up across affected areas to disseminate relevant technical know how.

\section{CONCLUSIONS}

In recent years, exploration of applications of automation and robotics to minimize the risk of disasters is becoming an interested area as the disasters, are occurring with increased frequency around the world and their impact in terms of human, structural and economic losses has increased considerably.

This is not an exception to Sri Lanka which was heavily affected by the Asian Tsunami in 2004. Among many other issues, post-disaster waste management is a key owing to capacity constraints of available resources including lands, expertise, funds and technology. Further, poor coordination and lack of communication led this to more critical status. Hence at the end of three years, still Sri Lanka is suffering form the impacts of tsunami 2004.

This paper provides a critical review on automation and robotics applications in waste at a post disaster scenario including the critical issues and available avenue for effective waste management for international concern.

\section{REFERENCES}

[1] UNEP (2005) Natural Rapid Environmental Assessment - Sri Lanka, UNEP Sri Lanka Country Report - 2005 .

[2] Scalem, M., \& Bandyopadhyay, S. (2005) Disaster Management: A model approach to an integrated real time computer mediated information Network system through wireless \& mobile networking as enabling technologies, abstract of the fellowship, Indian Institute of Management, Calcutta.

[3] Government of Sri Lanka and Development Partners, (2005) Post Tsunami Recovery and Reconstruction, Colombo, Ministry of Finance and Planning.

[4] Todd R. Pepper, (2007), "Waste Sampling Results Galle, Sri Lanka December 2005, ISWA/NVRD World Congress 2007. Sector: Landfill. Date: 24-27 September 2007. Location: Amsterdam, Netherlands.

[5] Scalem, M., Bandyopadhyay, S. \& Sircar, A. (2004) An approach towards a decentralized Disaster Management Information Network, Lecture Notes on Computer Science, Springer Publications, Volume No. 3285, No. AACC2004, October.

[6] Selvendran, P.G. \& Mulvey, C. (2005) Reducing solid waste and groundwater contamination after the tsunami, Daily news, Tuesday, 15 February

[7] Tabata, K., Inaba, A. \& Amano, H. (2005) Development of a transformational mobile robot to search victims under debris and rubble, Safety, Security and Rescue Robotics, Workshop, IEEE International Vol. 6 No. 9 19-24

[8] Fiedrich, F. \& Burghardt, P. (2007) Agent based systems for disaster management, Journal of communication of the ACM, Vol 50. No 3. 